\title{
Preparation and Assessment of Antimicrobial Property of Resin Based Composites Impregnated with Proanthocyanidin and Titanium Dioxide
}

\author{
Mumtaz ul Islam ${ }^{1}$ \\ Sardar Muhammad ${ }^{2}$ \\ Fazal Ghani $^{3}$
}

\author{
BDS, M.Phil \\ MBBS, DOMS, M.Phil \\ BSc, BDS, MSc, CMP, PhD, FDSRCPS (Post Humous)
}

OBJECTIVE: To synthesize three experimental resin based composites (RBCs) out of a commercial preperation (Control) by impregnating into each a fixed weight $(0.01 \%)$ of titanium dioxide $\left(\mathrm{TiO}_{2}\right)$ and three different weight $\%(0.01,0.02$ and 0.03$)$ of proanthocyanidin (PA) and to compare antibacterial property, from the zones of inhibition of streptococcus mutans (S. mutans), of the specimen restorations made in the experimental and control RBCs.

METHODOLOGY: In the first phase, Streptococcus mutans were isolated and identified from the oral cavity of patients and identified on the basis of morphogenic appearance of colonies and confirmed through catalase test and microscopic examination. Isolates were then incubated and cultured for sensitivity. Specimens for control and experimental RBCs were made through a metallic mold having $2 \mathrm{~mm}$ thickness and $5 \mathrm{~mm}$ diameter for all the 4 groups. Specimen restorations made in the commercial as supplied RBC acted as the control (Group A). Specimen restorations in the Group B, C, and D were made in each of the experimental RBCs modified with $0.01 \%$ proanthocyanidin $(\mathrm{PA})$ and $0.01 \%$ titanium dioxide $\left(\mathrm{TiO}_{2}\right), 0.02 \% \mathrm{PA}$ and $0.01 \% \mathrm{TiO}_{2}$ and $0.03 \% \mathrm{PA}$ and $0.01 \% \mathrm{TiO}_{2}$. The antimicrobial property of all the specimen restorations in all the groups was evaluated by Bauer-Kirby (Disc Diffusion) method through the formation of zones of inhibition of S. mutans colonies on blood agar plates. Data were computed using SPSS version 21 for descriptive statistics and analyzed using one-way ANOVA with $p$ value 0.05 taken as significant.

RESULTS: The range of the zone of inhibition for specimen $\mathrm{RBC}$ restorations $(\mathrm{N}=12)$ containing $\mathrm{PA}$ and $\mathrm{TiO}_{2}$ was 0.00 for Group A, 10-12mm for Group B, 12-14mm for Group C and 9-10mm for Group D. The mean inhibition zone for the experimental restoration specimens was $11 \pm 2 \mathrm{~mm}$ for Group B, $12.7 \pm 1 \mathrm{~mm}$ for Group $\mathrm{C}$ and $9.7 \pm 1 \mathrm{~mm}$ for Group D compared to no inhibition zones $(0.00 \mathrm{~mm})$ with the control RBC Group A. The order of the inhibition zones from maximum to minimum was Group C > Group B > Group D > Group A. The differences between the mean values for the control and the experimental RBC restoration specimens were significant $(\mathrm{p}<0.000)$. The specimen restorations in the Group D appeared under cured and could impact on their mechanical properties.

CONCLUSION: Irrespective of the mentioned concentrations, impregnating $\mathrm{PA}$ and $\mathrm{TiO}_{2}$ rendered the $\mathrm{RBC}$ antimicrobial. $\mathrm{RBC}$ restorations made with the experimental $\mathrm{RBC}$ with $0.02 \% \mathrm{PA}$ and $0.01 \% \mathrm{TiO}_{2}$ proved relatively more effective in terms of antimicrobial effect.

KEY WORDS: dental materials, resin based dental restorations, antibacterial resin based composite, proanthocyanidin, titanium dioxide.

HOW TO CITE: Islam MU, Muhammad S, Ghani F. Preparation and assessment of antimicrobial property of resin based composites impregnated with proanthocyanidin and titanium dioxide. J Pak Dent Assoc 2021;30(4):243-248.

DOI: https://doi.org/10.25301/JPDA.304.243

Received: 27 January 2021, Accepted: 17 August 2021

\section{INTRODUCTION}

$\mathrm{T}$ he involvement of microbes in the process of dental caries is well-established due to the virulence of streptococcus mutans. ${ }^{1-3}$ Dental resin based

1. Associate Professor, Head of Department, Science of Dental Materials, Abbottabad International Medical Institute, Dental Section, Abbottabad, Pakistan.

2. Associate Professor, Section Head Microbiology, Peshawar Medical College, Warsak Road Peshawar, Pakistan.

3. Dean \& Head of Department Prosthodontics, Peshawar Dental College, Warsak Road Peshawar, Pakistan.

Corresponding author: “Dr. Mumtaz ul Islam” < drmumtazulislam@gmail.com > composites (RBCs) suffers polymerization shrinkage, have lower strength and lack antimicrobial property. These have been noted to cause failure of the RBC restoration because of fracture as well as recurrent carries at the tooth-restoration interface. ${ }^{4}$ To address these issues, there is an ongoing research focus to produce RBCs with antimicrobial property. Antibacterial agents of bioactive nature, caries preventive additives, polymer antibiotic conjugates and quaternary ammonium salts were added in resins to elicit antimicrobial activity. ${ }^{4-9}$

The antioxidant action and free-radical scavenging 
effect of Proanthocyanidin (PA) have been established when applied to a surfaces. ${ }^{10}$ Cariogenic environment causing degradation of dentine has been prevented with PA. ${ }^{11}$ The antibacterial action of Titanium Dioxide $\left(\mathrm{TiO}_{2}\right)$ is through photo catalysis with water to release the hydroxyl radical with subsequent formation of superoxide as an antimicrobial agent. $^{12}$

Knowing the fact that there are inconsistencies in the literature regarding the antimicrobial property of RBCs, the search for making them antimicrobial is continue. ${ }^{13-14}$ Both PA and $\mathrm{TiO}_{2}$ are naturally occurring and easily available, hence their incorporation into RBC for possible antimicrobial property of the resulting restorations justifies an investigation. When proanthocyanidin was incorporated in adhesive agent in different concentrations ranging from $1 \%$ to $6 \%$ the antibacterial activity was same as of the control which is devoid of Proanthocyanidin. ${ }^{15}$ Antibacterial activity of $\mathrm{TiO}_{2}$ in concentrations from $0-10 \%$ was also evaluated in orthodontic composites which provided better antibacterial activity with concentration of $10 \%{ }^{16}$ Therefore, we have designed a comprehensive study that is looking at the effect of adding PA and $\mathrm{TiO}_{2}$ to $\mathrm{RBC}$ in terms of enhancement of antimicrobial and mechanical properties. This report presents the results on the antimicrobial effect of incorporating different concentrations of PA and a fixed quantity of $\mathrm{TiO}_{2}$ in $\mathrm{RBC}$ and assessing their antibacterial property of specimen restorations against $\mathrm{S}$. mutans isolated from the oral cavity of subjects.

\section{METHODOLOGY}

\section{Preparation of specimen restorations:}

Group A was the control group in which no additives were added. In each group 4 specimens were prepared from a commercially available RBC, Nexcomp (Meta Biomed Co. Ltd) with $1 \% \mathrm{TiO}_{2}$ which was fixed for all the experimental groups. Group B, C, \& D all were test groups which have 0.01, 0.02 and $0.03 \%$ PA. Sample size was calculated according to the following values the confidence level for this study was considered as $95 \%$ while power of the study kept 80 with a response distribution $60 \%$ and margin of error kept $5 \%$ the calculated sample size was 3 used in this pilot study.

The research protocol for the study was approved by the Board of Advanced Studies and Research (BASR) of the university (Riphah 25th meeting, dated, October, 18th, 2018) as well it was approved for publication of the research findings by the institutional review board (PRIME/IRB/ 2019-166.) The experimental work was conducted during the period of (01 May to 30 June, 2018) at the Department of Dental Materials and Microbiology Lab, Department of
Pathology, Peshawar Medical and Dental College (Pakistan). The materials used in the study including the experimental RBC are detailed in (Table 1).

Proanthocyanidin (PA) was characterized for purity using Fourier Transform Infrared Spectroscopy (FTIR) in Material Research Laboratory, Physics Department Peshawar University, Pakistan (Figure 1).

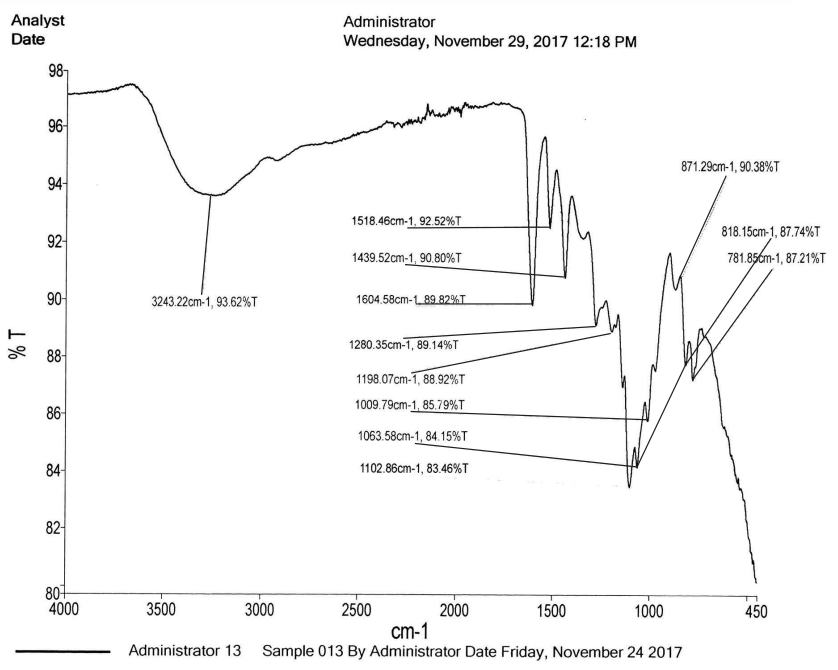

Figure 1

Each of the relevant weight $\%$ of $\mathrm{PA} \& \mathrm{TiO}_{2}$ were first assimilated in the resin bonding agent to facilitate easy and thorough mixing and then impregnated into a commercially available light-cure nanohybrid RBC NexcompNanohybrid Resin Composite Nexcomp contains Bis-GMA, Bis-EMA, UDMA, TEGDMA while Meta P\&Bond Adhesive contains Bisphenol A Glycerolate dimethacrylate, Urethane Dimethacrylate, Pyromellitic glyceryl dimethacrylate, 2-Hydroxy ethyl methacrylate, Ethyl alcohol (Table 1). The

Table 1: Details of the materials used

\begin{tabular}{|l|l|l|l|}
\hline Name of Material & Composition & Lot No & $\begin{array}{l}\text { Manufacturer } \\
\text { Name }\end{array}$ \\
\hline $\begin{array}{l}\text { Nexcomp } \\
\text { Nanohybrid } \\
\text { Resin Composite }\end{array}$ & $\begin{array}{l}\text { Bis-GMA, Bis-EMA, } \\
\text { UDMA, TEGDMA }\end{array}$ & Lot.No:NXC1706202 & $\begin{array}{l}\text { Meta Biomed } \\
\text { Co. Ltd. } \\
\text { Korea }\end{array}$ \\
\hline $\begin{array}{l}\text { Meta P\&Bond } \\
\text { Adhesive }\end{array}$ & $\begin{array}{l}\text { Bisphenol A } \\
\text { Glycerolate } \\
\text { dimethacrylate, } \\
\text { Urethane } \\
\text { Dimethacrylate, } \\
\text { Pyromellitic glyceryl } \\
\text { dimethacrylate, 2- } \\
\text { Hydroxy ethyl } \\
\text { methacrylate, Ethyl } \\
\text { alcohol }\end{array}$ & Lot.No:PNB1707182 & $\begin{array}{l}\text { Meta Biomed } \\
\text { Co. Ltd }\end{array}$ \\
\hline $\begin{array}{l}\text { Proanthocyanidin } \\
\text { Powder Capsules }\end{array}$ & & 17205 & \\
\hline $\begin{array}{l}\text { Titanium dioxide } \\
\text { Powder }\end{array}$ & & Lot No: T1264PI1 & $\begin{array}{l}\text { Daejung } \\
\text { Chemicals \& } \\
\text { Metals Co., } \\
\text { Ltd. Korea }\end{array}$ \\
\hline
\end{tabular}


three experimental RBCs were prepared by adding in each a fixed weight $\%$ of $\mathrm{TiO}_{2}(0.01 \%)$ and the various weight $\%$ of the PA $(0.01 \%, 0.02 \%$ and $0.03 \%)$ to the commercially supplied RBC. The as supplied commercial $\mathrm{RBC}$ acted as the control RBCs.

The specimen restorations were prepared in each of the three experimental and the control RBC using a stainless steel mold according to ISO specification No. 4049. The mold facilitated the preparation of specimens having $2 \mathrm{~mm}$ thickness with $5 \mathrm{~mm}$ diameter. Specimen restorations were made by pouring each of the RBC into the mold and cured with a light curing unit (O-Light by DTE, 5 watts, Light Intensity from 1000 to $2300 \mathrm{mw} / \mathrm{cm}^{2}$ ) for 20 seconds from one side. The poured resin was kept pressed under a $1 \mathrm{~mm}$

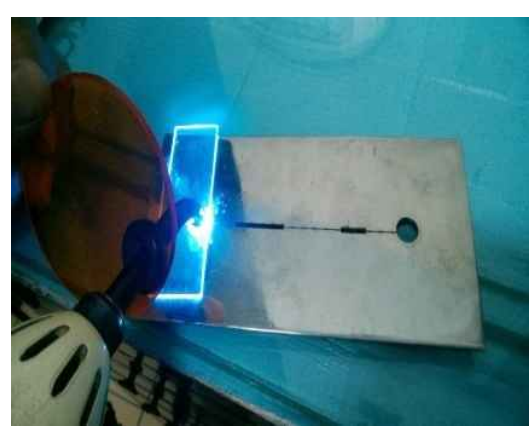

Figure 2 thick glass slab from both sides (Figure 2). After light-curing, the specimen restorations were recovered from the mold and ex a mined and finished (Figure 2) and when considered satisfactory as no specimen was under cured, no voids or cracks were present, they were then stored in dry sealed containers according to ISO 4049 specifications.

\section{Assessment of antibacterial property of the specimen restorations}

This was determined by Bauer-Kurby disc diffusion test using $\mathrm{S}$. mutans from the oral cavity of patients who were negative for $\mathrm{HbV}$ and $\mathrm{HcV}$ infection. Swabs were taken from carious teeth of patients to collect S. mutans. Written consents of patients were obtained and duly signed by witnesses. The swabs were transferred to Microbiology Department Peshawar Medical \& Dental College within

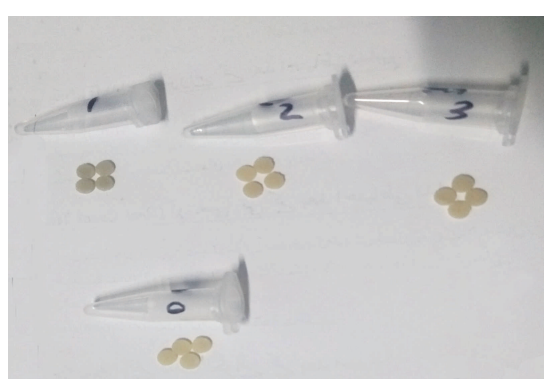

Figure 3 30 minutes in a sealed sterile tube. Strains of S. mutans were proliferated on sterile blood agar plates under optimum conditions and at $37^{\circ} \mathrm{C}$ for 24 hours and evaluated morphogenicallyconfirmed through catalase negative test and finally confirmed through microscopic evaluation (Figure 3).

Colonies of S. mutans were tested for sensitivity by placing the control and test specimen $\mathrm{RBCs}$ at different locations on blood agar plates having $\mathrm{S}$. mutans colonies (Figure 4). They were incubated at $37^{\circ} \mathrm{C}$ for 24 hours. After incubation period circular inhibition zones if any appeared specimens were d o c u m e n t e d. Inhibition zone sizes were recorded through taking photographs by using a scale marked with millimeters and placing the scale over the blood agar plates (Figure 5) and the data were recorded in a pre-structured data collection sheet.

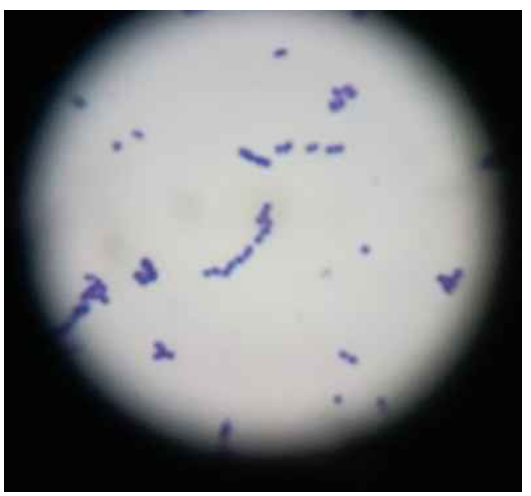

Figure 4

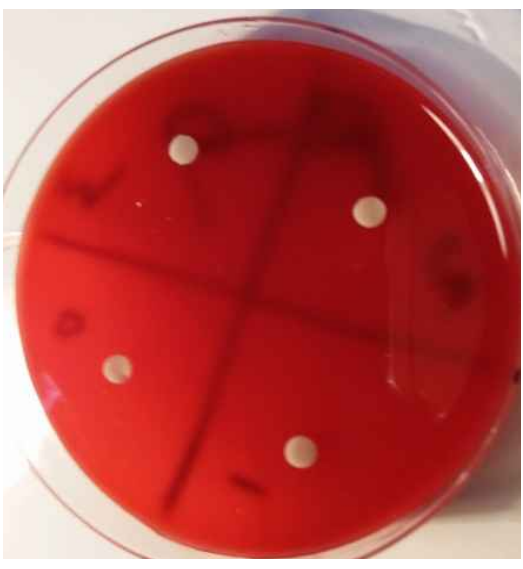

Figure 5 around the placed

\section{DATA ANALYSIS}

Using SPSS Version 21, mean, mode and percentages for the data were computed. Data were also analyzed using one-way ANOVA to see the statistical significance of the within and between the specimen groups differences from the mean values with $\mathrm{p}$ value set as 0.05 considered significant. Post hoc test is not presented due to selfexplanatory results of four groups of this pilot study.

\section{RESULTS}

The specimen restorations in the control group did not exhibit any antimicrobial property in-comparison to those in the experimental groups. Similarly, the antimicrobial property was maximum for the restoration specimens in group $\mathrm{C}$. The order of antibacterial effect among the specimens in the various groups was Group C > Group B > Group D > Group A. (Table 2).

The mean size of the inhibition zone was $8.42 \mathrm{~mm}$ for the specimens in groups B to D out of $13 \mathrm{~mm}$. Maximum sizes of inhibition zones were found in two specimen restorations belonging to group $\mathrm{C}$. None of the control group 
Table 2: Inhibition zones for the various RBC specimen restorations.

\begin{tabular}{|l|l|l|l|}
\hline $\begin{array}{l}\text { RBC } \\
\text { Specimen } \\
\text { restoration } \\
\text { group }\end{array}$ & $\begin{array}{l}\text { Inhibition zone } \\
\text { range }(\mathrm{mm})\end{array}$ & Mean \pm SD & mode \\
\hline A & $\mathbf{0 . 0 0 - 0 . 0 0}$ & $0.0 \pm 0.0$ & 0.00 \\
\hline B & $10.0-12.0$ & $11.0 \pm 2.0$ & 12 \\
\hline C & $12.0-14.0$ & $12.7 \pm 1.0$ & 13 \\
\hline D & $9.0-10.0$ & $9.7 \pm 1.0$ & 9 \\
\hline
\end{tabular}

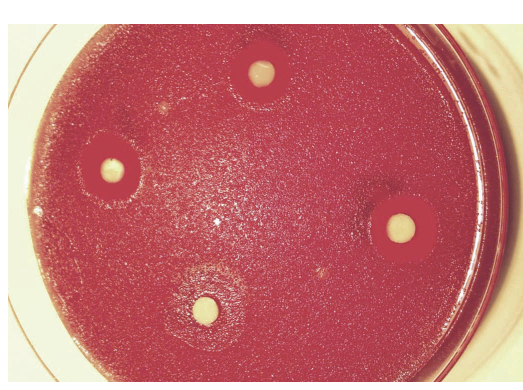

Figure 6 specimen restorations exhibited any antibacterial property (Table 2). Both the within group and between groups variations from the mean values were statistically significant $(\mathrm{p}=0.000)$. Different sized zone of inhibition were appearent which were then calculated (Figure 6).

\section{DISCUSSION}

For assessing the antimicrobial property of $\mathrm{RBC}$ restorative materials, the method of disc diffusion has also been previously used. ${ }^{17}$ Studies on anti-microbial property of experimental RBCs have used standardized microbial strains species like ATCC $35668^{18}$, ATCC $25175^{19}$ and a different strain of S. mutans (10449) has been used for assessing the antimicrobial effect of benzalkonium incorporated $\mathrm{RBC} .{ }^{20} \mathrm{~A}$ concern about these studies is that these have not mimicked the actual mode of action of the antimicrobial agent added to the resin. In this study strains of S. mutans collected from patient's mouth, making the testing method relatively more relevant because virulence/activity of standard cultures is questioned and reported as of low or no bacterial activity. ${ }^{21}$

At present, a definite methodology for testing antimicrobial properties of a material is lacking. Therefore, authors preferred the easy and commonly used method for this study. ${ }^{22}$ The disc diffusion method for establishing the antimicrobial efficacy of PA to S. mutans has also been used in another study. ${ }^{15}$ Quantitative methods like plate count method, flow cytometry and quantitative polymerase chain reaction for antimicrobial assessment are available but were not employed in the present study due to their technique sensitivity. ${ }^{23}$ Results obtained through disc diffusion method are better than other protocols. ${ }^{24}$ This was employed to verify the results obtained through direct contact test between microbial strains and the restorations and to validate the antibacterial action. Discs prepared for experimental and control RBC specimens had the same dimensions as used by other investigator. ${ }^{25}$ Furthermore, following the preparation of standardized specimen restorations and the selection of defect free specimens for testing obviated the need for using many specimens.

The incubation procedures employed for $\mathrm{S}$. mutans strains were according to the Bergey's manual of determinative microbiology. ${ }^{26}$ Due to vast discrepancy in literature for the growth medium and its yield, blood agar was used as nutrient medium for proliferation of the $S$. mutans colonies and their killing by the $\mathrm{RBC}$ specimen restorations. There is a positive correlation between genotype and phenotype evaluation of bacteria which confirms and validate the phenotypic evaluation of the

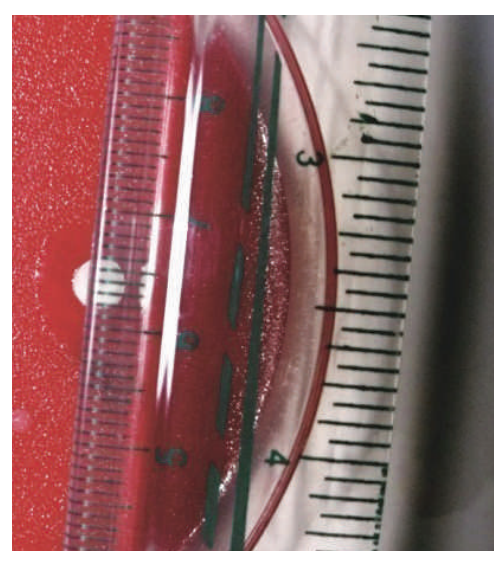

Figure 7 bacterium. ${ }^{16}$ The colonies obtained after incubation were identified in the present study for morphology of the colony followed by confirmation through catalase test and finally through microscopic examination (Figure 2).

The findings of the present study are in accordance with those of a previous study, in which the range of size of zones of inhibition was $9.33 \mathrm{~mm}$ to $12.67 \mathrm{~mm}$ for antibacterial activity of resin containing $0.25 \%$ concentration of benzalkonium chloride. ${ }^{20}$ Size of zones of inhibition always will be more than the size of discs if smaller than discs then it will be of no use and considered as no zone of inhibition. When a drug is placed in a medium where a bacterial culture is present if that drug is of antibacterial potential it produces areas of no growth around that drug specimen these areas are zones of inhibition. The findings of the present study are more encouraging as a comparable yet better antimicrobial effect has been achieved with a small concentration of PA $(0.02 \%)$. Our finding of the lack of antibacterial property in the specimen restoration made in the control RBC are supported by the finding of another study where no zones of inhibition were also observed in case of specimen restorations in the control $\mathrm{RBC}{ }^{27}$

In the present study, the RBC specimens in the control group exhibited no antibacterial effect as observed from no zones of inhibitions. In the present study a much lower concentration of $\mathrm{TiO}_{2}$ and PA showed comparable antibacterial activity. In the present study lower concentration of PA $(0.01,0.02$ and $0.03 \%)$ were used and found effective against $\mathrm{S}$. mutans. 
As titanium dioxide is highly opaque material therefore its concentration in the RBC was kept $0.01 \%$ so as to avoid the problem of shade change which was confirmed through another pilot study.

\section{LIMITATIONS OF THE STUDY}

An obvious limitation of this study may be the use of few samples and using a method for antimicrobial properties of the test RBCs restorations that does not mimic the real clinical situation in which the restorations are functioning. However, in case of in-vitro studies, using standardized dimension specimens that are defect-free, the use of few specimen restorations is justifiable. On the other side, in the present study, the specimen RBC restorations have been subjected to relatively harsher bacterial insult than that could be expected in the oral cavity. Despite this, it was encouraging to have seen enhanced antibacterial property in case of experimental $\mathrm{RBC}$ restorations containing PA and $\mathrm{TiO}_{2}$.

Incorporation of additives in $\mathrm{RBC}$ may produce any effect on the mechanical properties which was not evaluated in current study. This aspect is being currently under investigation for the experimental RBCs used in this study. Another limitation, of this study is the addition of PA and $\mathrm{TiO}_{2}$ to the commercial RBC, which have altered the actual formulation of the commercial RBC. Therefore, it is recommended that this aspect should be kept in mind in future studies by synthesizing the experimental RBC with the mentioned additives.

Another limitation of this study is that the antimicrobial effect has not been followed up over a larger duration of time and hence the sustained long term antibacterial effect of the RBC restorations cannot be predicted from the present study making observation at one time-point. It is recommended that the specimen restorations be tested repeatedly after simulated usage scenarios to give a clear picture of how much stable and long-lasting would be the observed antibacterial property as documented in this study.

\section{CONCLUSION}

Within limitations of this study, $\mathrm{PA}$ and $\mathrm{TiO}_{2}$ imparted antimicrobial properties to the RBC especially PA $0.02 \%$ along with $\mathrm{TiO}_{2} 0.01 \%$ which produced larger zones of inhibitions.

\section{CONFLICT OF INTEREST}

None declared.

\section{AUTHORSHIP CONTRIBUTIONS}

All authors (MUI, FG, MS) contributed equally to conception, design, data acquisition, analysis, and interpretation, drafted and critically revised the manuscript; All authors have given final approval and have agreed to be accountable for all the aspects of the research work and its publication. FG had accepted the responsibility as the corresponding author but after his unfortunate death MUI is now corresponding author.

\section{REFERENCES}

1. Clarke JK. On the bacterial factor in the etiology of dental caries. Br J Exp Pathol. 1924;5:141-47.

https://www.ncbi.nlm.nih.gov/pmc/articles/PMC2047899/pdf/brjexp pathol00285-0021.pdf

2. Napimoga MH, Hofling JF, Klein MI, Kamiya RU, Goncalves RB. Transmission, diversity and virulence factors of Streptococcus mutans genotypes. J Oral Sci. 2005;47:59-64.

https://doi.org/10.2334/josnusd.47.59

3. Marsh PD, Head DA, Devine DA. Dental plaque as a biofilm and a microbial community implications for treatment. J Oral Biosci. 2015;57:185-191.

https://doi.org/10.1016/j.job.2015.08.002

4. Zhou W, Liu S, Zhou X, Hannig M, Rupf S, Feng J, Peng X, Cheng L. Modifying adhesive materials to improve the longevity of resinous restorations. Int J Mol Sci. 2019;20:723-29.

https://doi.org/10.3390/ijms20030723

5. Li F, Weir MD, Fouad AF, Xu HH. Time-killbehaviour against eight bacterial species and cytotoxicity of antibacterial monomers. J Dent. 2013;41:881-891

https://doi.org/10.1016/j.jdent.2013.07.006

6. Imazato S. MaS. Chen JH, \&Xu H H. Therapeutic polymers for dental adhesives: loading resins with bio-active components. Dent Mater. 2014;30:97-104.

https://doi.org/10.1016/j.dental.2013.06.003

7. Hetrodt F, Lausch J, Meyer-Lueckel H, Conrads G, Apel C. Evaluation of restorative materials containing preventive additives in a secondary caries model in vitro. Caries Res. 2019;53:447-56.

https://doi.org/10.1159/000496401

8. Zhang R, Jones MM, Moussa H, Keskar M, Huo N, Zhang Z, Visser MB, Sabatini C, Swihart MT, Cheng C. Polymer-antibiotic conjugates as antibacterial additives in dental resins. Biomater Sci. 2019;7:28795.

https://doi.org/10.1039/C8BM01228H

9. Li F, Weir MD, Chen J, Xu HH. Effect of charge density of bonding agent containing a new quaternary ammonium methacrylate on antibacterial and bonding properties. Dent Mater. 2014;30:433-41. https://doi.org/10.1016/j.dental.2014.01.002 
10. Balalaie A, Rezvani MB, Basir MM. Dual function of proanthocyanidins as both MMP inhibitor and crosslinker in dentin biomodification: A literature review. Dent Mater J. 2018;37:173-182. https://doi.org/10.4012/dmj.2017-062

11. Cai J, Palamara JE, Burrow MF. Effects of collagen crosslinkers on dentine: A literature review. Calcif Tissue Int. 2018;102:265-279. https://doi.org/10.1007/s00223-017-0343-7

12. Besinis A, De Peralta T, Handy RD. The antibacterial effects of silver, titanium dioxide and silica dioxide nanoparticles compared to the dental disinfectant chlorhexidine on Streptococcus mutans using a suite of bioassays. Nanotoxicology. 2014;8:1-16.

https://doi.org/10.3109/17435390.2012.742935

13. Cocco AR, da Rosa WL, da Silva AF, Lund RG, Piva E. A systematic review about antibacterial monomers used in dental adhesive systems: Current status and further prospects. Dent Mater. 2015;31:1345-362.

https://doi.org/10.1016/j.dental.2015.08.155

14. Ozel E, Kolayli F, Tuna EB, ErD. In vitro antibacterial activity of various adhesive materials against oral streptoccci. Biotechnol Equip. 2016;30:121-26.

https://doi.org/10.1080/13102818.2015.1090296

15. Dias PG, da Silva EM, Carvalho CM, Miranda MEDS, Portela MB, Amaral CM. Characterization and Antibacterial Effect of an Experimental Adhesive Containing Different Concentrations of Proanthocyanidin. J Adhes Dent. 2020;22:139-47. PMID: 32322835. https://doi.org/10.3290/j.jad.a44280

16. Sodagar A, Akhoundi MSA, Bahador A, Jalali YF, Behzadi Z, Elhaminejad F, Mirhashemi AH. Effect of TiO2 nanoparticles incorporation on antibacterial properties and shear bond strength of dental composite used in Orthodontics. Dental Press J Orthod. 2017;22:67-4.

https://doi.org/10.1590/2177-6709.22.5.067-074.oar

17. De Luca MP, Franca JR, Macedo FA, Grenho L, Cortes ME, Faraco AA, Moreira AN, Santos VR. Propolis varnish: antimicrobial properties against cariogenic bacteria, cytotoxicity, and sustainedrelease profile. BioMed Res Int. 2014;2014.

https://doi.org/10.1155/2014/348647

18. Wassel MO, Khattab MA. Antibacterial activity against Streptococcus mutans and inhibition of bacterial induced enamel demineralization of propolis, miswak, and chitosan nanoparticles based dental varnishes. J Adv Res. 2017;8:387-92.

https://doi.org/10.1016/j.jare.2017.05.006

19. AydinSevinc B, Hanley L. Antibacterial activity of dental composites containing zinc oxide nanoparticles. J Biomed Mater Res B Appl Biomater. 2010;94:22-31.

https://doi.org/10.1002/jbm.b.31620

20. Sodagar A, Akhavan A, Hashemi E, Arab S, Pourhajibagher M, Sodagar K, Kharrazifard MJ, Bahador A. Evaluation of the antibacterial activity of a conventional orthodontic composite containing silver/hydroxyapatite nanoparticles. Prog Orthod. 2016;17:40-6. https://doi.org/10.1186/s40510-016-0153-x

21. Munshi AK, Reddy NN, Shetty V. A comparative evaluation of three fluoride varnishes: an in-vitro study. J Indian Soc Pedod Prev Dent. 2001;19:92-102. PMID: 11817800.

22. Saito K, Hayakawa T, Kawabata R, Meguro D, Kasai K. In vitro antibacterial and cytotoxicity assessments of an orthodontic bonding agent containing benzalkonium chloride. Angle Orthod. 2009;79: 331-37.

https://doi.org/10.2319/120907-578.1

23. Bergeron MG, Ouellette M. Preventing antibiotic resistance through rapid genotypic identification of bacteria and of their antibiotic resistance genes in the clinical microbiology laboratory. J Clin Microbiol. 1998;36:2169-172. PMID:9665984.

https://doi.org/10.1128/JCM.36.8.2169-2172.1998

24. Chen L, Shen H, Suh BI. Antibacterial dental restorative materials: a state-of-the-art review. Am J Den. 2012;25:337-46. PMID: 23409624.

25. Li F, Weir MD, Chen J, Xu HH. Comparison of quaternary ammonium containing with nano silver containing adhesive in antibacterial properties and cytotoxicity. Dent Mater. 2013;29:45061.

https://doi.org/10.1016/j.dental.2013.01.012

26. Hamouda IM, Al-Khodary AM, Shami FM. Degree of conversion and antimicrobial activity of etch and rinse versus self-etching adhesives. J Adhes Dent. 2010;12: 33-38.

https://doi.org/10.3290/j.jad.a17535.

27. Carroll KC, Leonard RB, Newcomb-Gayman PL, Hillyard DR. Rapid detection of the staphylococcal mec A gene from BACTEC blood culture bottles by the polymerase chain reaction. AmJClinPathol. 1996;106:600-05.

https://doi.org/10.1093/ajcp/106.5.600

28. Holt JG, Krieg NR, Sneath PH, Staley JT. Bergey's manual of determinative bacteriology 9th Edition, Williams and Wilkins. ISBN 0-68300-6032, Baltimore, Maryland, USA; 1994 OCLC Number: 28183643 .

29. Almaroof A, Niazi SA, Rojo L, Mannocci F, Deb S. Influence of a polymerizable eugenol derivative on the antibacterial activity and wettability of a resin composite for intracanal post cementation and core build-up restoration. Dent Mater. 2016;32:929-39.

https://doi.org/10.1016/j.dental.2016.04.001

30. Pourhajibagher M, Vaziri AS, Takzaree N, Ghorbanzadeh R. Physico-mechanical and antimicrobial properties of an orthodontic adhesive containing cationic curcumin doped zinc oxide nanoparticles subjected to photodynamic therapy. Photodiagnosis and photodynamic therapy. 2019;25:239-46.

https://doi.org/10.1016/j.pdpdt.2019.01.002 